\title{
BIOLOGICAL
}

\section{Semantic, repetition and rime priming between spoken words: behavioral and electrophysiological evidence}

\author{
Monique Radeau $^{\mathrm{a},{ }^{*}}$, Mireille Besson ${ }^{\mathrm{b}}$, Elisabeth Fonteneau ${ }^{\mathrm{c}}$, \\ Sao Luis Castro ${ }^{\mathrm{d}}$ \\ ${ }^{a}$ FNRS, Brussels, Belgium \\ ${ }^{\mathrm{b}}$ CNRS-LNC, Laboratoire de Neurosciences Cognitives, 31 Chemin Joseph Aiguier, 13402 Marseille, \\ Cedex 20, France \\ ${ }^{c}$ Université de Genève, Genève, Switzerland \\ ${ }^{\mathrm{d}}$ Universidade do Porto, City, Portugal
}

Received 24 November 1997; received in revised form 19 January 1998; accepted 26 January 1998

\section{Abstract}

Semantic, phonological and repetition priming for auditorily presented words were examined, using both behavioral reaction times (RTs) and electrophysiological event-related potentials (ERPs) measures. On critical trials, a word prime was followed by a word target that was semantically or phonologically related (rime) or not related (control) to the prime. Pairs of word-pseudoword items served as fillers. Participants were asked to respond to word targets in the RT experiment and to pseudowords in the ERP experiment. In each experiment stimuli were presented once and then repeated in the very same way. RTs were found to be fastest for semantic, intermediate for rime and slowest for control targets; large repetition effects occurred for all targets. ERPs results showed that both semantic and phonological priming influenced the same component, namely the N400, whose amplitude was smallest to semantic, intermediate to rime and largest to control targets; repetition effects were only found for semantic trials. () 1998 Elsevier Science B.V. All rights reserved.

\footnotetext{
* Corresponding author. Present address. LAPSE-ULB, CP 191, 50 Av. F. Roosevelt, 1050 Bruxelles, Belgium. Tel.: + 322 6502539; fax: + 322 6502209; e-mail: moradeau@ulb.ac.be

0301-0511/98/\$19.00 @ 1998 Elsevier Science B.V. All rights reserved. PII S0301-0511(98)00012-X
} 
Keywords: Semantic priming; Phonological priming; Auditory word recognition; Event related potentials (ERPs); N400

Since the study of Meyer and Schvaneveldt (1971) demonstrating that a target word (e.g. BUTTER) is recognized faster when preceded by an associated prime (e.g. BREAD) than by a non-associate (e.g. NURSE), the so-called semantic priming effect has been extensively replicated in written word recognition, especially for associatively related pairs (Lupker, 1984; Neely, 1990). It was later demonstrated between spoken words, using the lexical decision task (Radeau, 1983) and single word shadowing (Slowiaczek, 1994), and was shown to occur across sensory modalities, for example, between an auditory prime and a visual target (Swinney et al., 1979).

The priming paradigm serves not only to investigate the influence of semantic associations but also of formal relations between items. The underlying idea is that when the overlap coincides with a unit whose representation is involved in word recognition, activation of such a unit presented as prime may affect the processing of a following target. In the case of auditorily presented words, due to the special status attributed by the first version of the 'Cohort model' to word initial information (Marslen-Wilson and Welsh, 1978), most of the formal priming studies have been concerned with the role of initial phonological overlap between prime and target. However, effects going in different directions (from inhibition to facilitation) or, more often, no effect at all have been reported (Slowiaczek and Pisoni, 1986; Radeau et al., 1989; Slowiaczek and Hamburger, 1992; Goldinger et al., 1992; Praamstra et al., 1994; Radeau et al., 1995). In contrast, in studies where final phonological overlap was examined, facilitation was consistently found between items that shared the last syllable in bisyllabic items (Emmorey, 1989) or at least the rime in monosyllabic items (Praamstra et al., 1994; Radeau et al., 1995), and this whatever the task.

It seems that the final overlap effect does not take place at the level of the semantic lexicon but taps earlier stages of processing. Radeau et al. (1994), using the same monosyllabic items as Radeau et al. (1995) did not find any effect of rime overlap with a crossmodal procedure in which the prime was presented auditorily and the target visually. While an effect located at, or after, the level of the semantic lexicon, which is presumably amodal, is expected to be of comparable size under unimodal or crossmodal presentation, an effect located at an earlier stage should be modality dependent.

Disorders of spoken word recognition, like 'word meaning deafness' in brain injured patients without concomitant impairment in reading, led neuropsychologists to assume separate input lexicons for auditory and visual words (cf. Ellis and Young, 1988, for a review). These lexicons would receive inputs from the auditory and visual analysis systems, respectively, and contain stored representations of familiar heard and written words, the meaning of the words being stored in a 
common semantic system. Neuroanatomical data, using brain imaging techniques like positron emission tomography (PET), suggest that different areas are involved in the visual and auditory coding of words. At the sensory level, the acoustic analysis would take place in the superior temporal gyrus which includes the primary and secondary auditory cortex (Zatorre et al., 1992; Mazoyer et al., 1993), and the visual analysis in the extrastriate cortex (Petersen et al., 1988, 1990). What Petersen et al. (1988) call 'the auditory (or phonological) and visual (or orthographic) word form systems' would be localized in different areas for which there is, however, no complete agreement between the authors (Petersen et al., 1988, 1990; Zatorre et al., 1992; Howard et al., 1992). Furthermore for semantic processing, the data are even more conflicting. While some studies found activation in areas of the pre-frontal cortex (Petersen et al., 1988, 1990; Mazoyer et al., 1993), other studies provided evidence for the contribution of temporal areas, especially Wernicke's area (Wise et al., 1991; Démonet et al., 1992). Recently, Fiez et al. (1996) also found data consistent with the later result. They conclude that the temporal areas activated by semantic and phonological processing, while being close neighbors, are functionally and spatially dissociated.

The finding of crossmodal associative semantic priming together with the lack of crossmodal rime priming thus suggest that the two kinds of priming tap different levels of processing. The experiments reported in this paper were designed to gain further evidence concerning the nature of the processes involved in semantic and rime priming between spoken words, using two different methodologies: chronometric measures (Experiment 1) and ERPs recordings (Experiment 2). ERPs allow real-time analysis of the changes in the brain electrical activity that are time-locked to information processing. Furthermore, the high temporal resolution of ERPs allows to distinguish various components in the brain cortical activity that reflect different stages of information processing. Therefore, the first aim of Experiment 2 was to determine whether semantic and rime priming influence the same or different ERP components.

The ERP components associated with semantic priming have been well documented. In the case of printed words, a negative ERP peaking at $400 \mathrm{~ms}$ (N400) after target onset has been shown to reflect semantic processing. A reduction in the amplitude of the $\mathrm{N} 400$ associated with semantic priming was first described in sentence contexts (Kutas and Hillyard, 1980; Besson et al., 1992; Mitchell et al., 1993) and later in single word contexts (Bentin et al., 1985; Nobre and McCarthy, 1994). For spoken language, where ERP data are still relatively scarce, a N400 reduction associated with semantic priming has also been reported (Holcomb and Neville, 1990; Bentin et al., 1993; Besson et al., 1997).

The electrophysiological correlate of phonological priming is less well documented. It was first studied for visually presented pairs of riming and non-riming words and nonwords (Rugg, 1984). The results of this experiment showed that the amplitude of a negative component, peaking around $450 \mathrm{~ms}$, was larger for non-riming than riming words and nonwords. Based on this finding, Rugg (1984) argued that N400 components are not only associated with semantic mismatches, but are also elicited in response to phonological mismatches. The same conclusion 
was recently reached for auditorily presented words by Praamstra et al. (1994) in a study in which chronometric measures showed facilitatory effect of final phonological overlap (rime) but no effect of initial phonological overlap (alliteration), using the auditory lexical decision task. In contrast, analysis of the ERP data showed that both rime and alliteration effects were significant but their time course was different. The reduction in the amplitude of a negative component occurred earlier for initial than for final overlap. The authors hypothezised that both effects could represent changes in the same component, possibly the N400. O'Rourke and Holcomb (1992) have also shown that the onset latency of the N400 is sensitive to the point in time when spoken items became pseudowords. Taken together, these results demonstrate that the $\mathrm{N} 400$ is sensitive to the time course of spoken word recognition and that ERPs may provide a more sensitive measure of phonological priming than behavioral measures alone (RTs and percent correct).

The second aim of the study was to investigate whether semantic and rime priming would be similarly influenced by repetition. Results of numerous experiments have shown that visually presented words are responded to faster and more accurately on their second than first occurrence (e.g. Scarborough et al., 1977). In the ERPs, the repetition effect is generally associated with a decrease in the amplitude of the N400 component and an increase in the subsequent Late Positive Component (LPC; e.g. Besson et al., 1992; Rugg, 1987). Again, however, most of the studies have been conducted in the visual modality (Monsell, 1985) and it was of interest to further study the characteristics of repetition effects in the auditory modality (Ellis, 1982; Rugg et al., 1995).

\section{Experiment 1}

The primary goal of Experiment 1 was to examine semantic and phonological priming, focusing on rime (final) overlap and using reaction times and accuracy as dependent variables. Participants were required to perform an auditory lexical decision task (decide whether the second stimulus in a pair was a word or not) with response to words only. Stimuli were presented twice so as to study repetition effects.

\section{1. Method}

\section{1. 1. Participants}

Thirty students, nine males and 21 females (mean age: 20.5 years; range: 18-25 years), from the Free University of Brussels, participated in the experiment as part of an introductory psychology course. All participants were native French speakers and reported no hearing defect.

\subsubsection{Materials}

Sixty quadruplets of words served as critical items, one of the quadruplet was used as target and the other three as primes (see Appendix A). They were selected 
using BRULEX (Content et al., 1990), a lexical database for French. All words were monosyllabic, two, three or four phonemes long. Threekinds of primes were used that were semantically related to the target (semantic primes), phonologically related (rime primes) or semantically not related with no phoneme in common (control primes). Semantic primes were selected in part from the norms of word association reported for French by Rosenzweig (1970) and in part from unpublished norms collected from students of the Free University of Brussels. Rime primes were words phonologically related to the target by their last vowel and following a consonants. In some cases, for items beginning by a $\mathrm{CC}$ cluster, prime and target also shared the second consonant of the onset. Sixty pairs of items consisting of a word and a pseudoword served as fillers, the word being always used as prime and the pseudoword as target. They were also monosyllabic, two to four phonemes long.

\subsubsection{Procedure}

The items were recorded by a male native speaker of French in a soundproof room on a D/A converter with a Neumann U-87 microphone. They were digitized at a sampling rate of $32 \mathrm{kHz}$ and with 16-bit analog-to-digital conversion, using the editor 'Sound Tools' on a Macintosh II FX computer. The stimuli were transferred to the left channel of a Sony 55ES D/A converter. They were stored as pairs of corresponding primes and targets, with a $4 \mathrm{~s}$ SOA between the onset of the primes of two consecutive pairs. There was a $20 \mathrm{~ms}$ silence interval between the offset of the prime and the onset of the target of each pair. A square wave click starting 20 ms before the onset of each target was stored on the right channel of the D/A converter. This inaudible click triggered the computer clock-card after $20 \mathrm{~ms}$ to record RTs (in Experiment 1) and ERPs (in Experiment 2). Thus, both RTs and ERP recordings were time-locked to target onset. Mean target duration was $574 \mathrm{~ms}$ (range: 276-744 ms). Presentation of the items and data collection were controlled by an Apple IIe computer connected to the D/A converter. Stimuli were presented to the participant at a comfortable level through a pair of Beyer DT-202 headphones connected to the left channel of the D/A converter.

Three lists of items were constructed in which the three types of overlap had the same probability of occurrence; an item was presented only once. Each list included 60 critical trials consisting of 20 semantic, 20 rime and 20 control pairs. Sixty pairs of word-pseudoword items were also used as fillers in the three lists. The order of occurrence of the stimuli was determined randomly with the restriction that any specific condition semantic, rime, control or pseudoword) did not occur more than three times consecutively. The three lists were heard by different groups of 10 participants each. In each group, two different orders of succession of the stimuli were heard by two different subgroups of five participants.

The participants were tested individually in a quiet room. They were told that the first item of each pair would always be a word, but that the second item could be a word or a pseudoword. Their task was to respond to the second item when it was a word. No response was required to pseudowords. The participants were asked to press a key to target words with their preferred hand, as quickly and accurately as possible. The response key was interfaced to the computer via the game connector. 
In order to study auditory word repetition effects, each list of items was presented two times using an identical order of item presentation. There was a 5 min break between the two presentations. Since each list lasted for about $15 \mathrm{~min}$, the time lag between two occurrences of a given item was about 20 min. Twelve practice trials were presented at the beginning of the session.

\subsection{Results}

RTs were computed from target onset to response onset. RTs longer than 1500 $\mathrm{ms}$ or shorter than $200 \mathrm{~ms}$ and incorrect responses were discarded from the analyses.

Mean RTs and error rates are presented in Table 1. Strong facilitatory priming effects were found on RTs for both related conditions, with the size of the semantic priming effect $(172 \mathrm{~ms})$ being almost two times that of the rime effect $(95 \mathrm{~ms})$. Furthermore, both effects were larger on second than first presentation $(214 \mathrm{~ms}$ and $125 \mathrm{~ms}$ for semantic and phonological priming on second presentation, respectively). For each presentation, mean RTs and error rates per subject and per item were analyzed using Analyses of Variance (ANOVAs) with Prime Type (semantic, rime and control) as factor. By convention, the $F$ values are referred to as $F_{1}$ or $F_{2}$ for the subject or item analyses, respectively.

\subsection{First presentation}

The ANOVA performed on RTs showed a significant effect of Prime Type $\left(F_{1}\right.$ $\left.(2,58)=164.01, \mathrm{MSe}=1358, p<0.001 ; F_{2}(2,118)=61.43, \mathrm{MSe}=7488, p<0.001\right)$ RTs were faster to semantic than control trials $\left(F_{1}(1,29)=283.6\right.$, MSe $=1564$, $p<0.001$ and $\left.F_{2}(1,59)=125, \mathrm{MSe}=7338, p<0.001\right)$ and to rime than control Trials $\left(F_{1}(1,29)=110.6\right.$, MSe $=1233, p<0.001$ and $F_{2}(1,59)=52.4$, Mse $=5229$, $p<0.001)$. There were also faster RTs for semantic than rime trials $\left(F_{1}(1,29)=\right.$ $68.9, \mathrm{MSe}=1275, p<0.001$ and $\left.F_{2}(1,59)=19.1, \mathrm{MSe}=9894, p<0.001\right)$.

ANOVAs on error rates yielded a significant effect of Prime Type $\left(F_{1}(2,58)=\right.$ $\left.7.02, \mathrm{MSe}=.90, p<0.001 ; F_{2}(2,118)=7.11, \mathrm{MSe}=0.48, p<0.001\right)$. The effect was due to error rates being significantly higher for the control than for the semantic condition $\left(13.5 \% ; F_{1}(1,29)=13.90\right.$, MSe $0.87, p<0.001 ; F_{2}(1,59)=$

Table I

Mean RTs and error rates in the three conditions of Experiment 1

\begin{tabular}{llccccc}
\hline \multirow{2}{*}{ Presentation } & \multicolumn{2}{l}{ Trial } & & & \multicolumn{3}{c}{ Control versus } \\
& \multicolumn{1}{l}{ Semantic } & & Rime & Control & Semantic & Rime \\
& RT & 656 & 732 & 828 & 172 & 96 \\
\hline First & $\%$ errors & 2.0 & 11.0 & 15.5 & 13.5 & 4.5 \\
& RT & 592 & 681 & 806 & 214 & 125 \\
Second & $\%$ errors & 4.0 & 5.5 & 15.5 & 11.5 & 10.0 \\
& & & & & & \\
\hline
\end{tabular}


15.13, MSe $=0.43 p<0.001)$, and for the rime than for the semantic condition $\left(9.0 \% ; F_{1}(1,29)=13.50, \mathrm{MSe}=0.40, p<0.001 ; F_{2}(1,59)=8.26\right.$, MSe $=0.36$, $p<0.001)$. The $4.5 \%$ difference in error rate between the rime and control conditions did not reach significance (both $F<1$ ).

\subsubsection{Second presentation}

For RTs, the pattern of results was the same as for first presentation. The effect of Prime type was significant $\left(F_{1}(2,58)=179.15\right.$, MSe $=1934, p<0.001 ; F_{2}$ $(2,118)=97.55, \mathrm{MSe}=7137, p<0.001)$. RTs were $214 \mathrm{~ms}$ faster to semantic than control trials $\left(F_{1}(1,29)=264.1, \mathrm{MSe}=2599, p<0.001\right.$ and $F_{2}(1,59)=211.1$, $\mathrm{MSe}=6541, p<0.001), 125 \mathrm{~ms}$ faster to rime than control trials $\left(F_{1}(1,29)=160,8\right.$ MSe $=1454, p<0.001$ and $\left.F_{2}(1,59)=92.7, \mathrm{MSe}=5001, p<0.001\right)$, and $89 \mathrm{~ms}$ faster to semantic than rime trials $\left(F_{1}(1,29)=68.1, \mathrm{MSe}=1747, p<0.001\right.$ and $F_{2}$ $(1,59)=24.74, \mathrm{MSe}=9866, p<0.001)$.

For error rates, the pattern of results was also similar to first presentation. The effect of Prime Type was significant $\left(F_{1}(2,58)=6.60\right.$, MSe $=0.70, p<0.001$ $\left.F_{2}(2,118)=4.92, \mathrm{MSe}=0.44, p<0.05\right)$. Error rates were significantly higher for the control than for semantic targets $\left(11.5 \% ; F_{1}(1,29)=11.27\right.$, MSe $=0.78, p<0.001$; $\left.F_{2}(1,59)=9.53, \mathrm{MSe}=0.42 p<0.001\right)$, and for control than rime targets $(10.0 \%$; $\left.F_{1}(1,29) 4.46, \mathrm{MSe}=0.95, p<0.001 ; F_{2}(1,59)=4.08, \mathrm{MSe}=0.52, p<0.05\right)$ However, the $1.5 \%$ difference in error rate between the rime and semantic conditions did not reach significance $\left(F_{1}(1,29)=2.21\right.$, MSe $\left.=0.37 ; F_{2}<1\right)$.

\subsubsection{Joint analyses of first and second presentation}

ANOVAs with Presentation (two levels) and Prime Type (three levels) as factors showed significant effects of Prime Type $\left(F_{1}(2,58)=198.19\right.$, MSe $=2837, p<$ $\left.0.001 ; F_{2}(2,118)=88.87, \mathrm{MSe}=12869, \mathrm{p}<0.001\right)$ and Presentation $\left(F_{1}(1,29)=\right.$ $\left.30.78, \mathrm{MSe}=3024, p<0.001 ; F_{2}(1,59)=90.37, \mathrm{MSe}=2200, p<0.001\right)$. Overall, RTs were $45 \mathrm{~ms}$ faster on second than first presentation. Furthermore, the effects of Prime Type and Presentation interacted significantly $\left(F_{1}(2,58)=15.30\right.$, MSe $=$ $\left.455, p<0.001 ; F_{2}(2,118)=7.17, \mathrm{MSe}=1756, p<0.001\right)$ with larger repetition effects for both semantic $(64 \mathrm{~ms})$ and rime $(51 \mathrm{~ms})$ than control targets $(22 \mathrm{~ms})$ but no difference between semantic and rime targets (semantic vs control: $F_{1}(1,29)=$ 27.93, $\mathrm{MSe}=473, p<0.001$ and $F_{2}(1,59)=11.90, \mathrm{MSe}=1983, p<0.001$; rime vs control: $F_{1}(1,29)=20.60, \mathrm{MSe}=316, p<0.001$ and $F_{2}(1,59)=6.37$, MSe $=1984$ $p<0.001)$. Note, however, that the effect of repetition was significant for all three types of target, semantic $\left(F_{1}(1,29)=28.82\right.$, MSe $=2108, p<0.001$ and $F_{2}(1,59)=$ 74.47, $\mathrm{MSe}=1643, p<0.001)$, rime $\left(F_{1}(1,29)=42.09, \mathrm{MSe}=932, p<0.001\right.$, and $\left.F_{2}(1,59)=40.58, \mathrm{MSe}=2071, p<0.001\right)$ and control $\left(F_{1}(1,29)=7.87, \mathrm{MSe}=895\right.$, $p<0.001$ and $\left.F_{2}(1,59)=8.80, \mathrm{MSe}=1998, p<0.001\right)$.

ANOVAs on error rates yielded a significant effect of Prime Type $\left(F_{1}(2,58)=\right.$ $\left.8.15, \mathrm{MSe}=1.28, p<0.001 ; F_{2}(2,118)=7.04, \mathrm{MSe}=0.74, p<0.001\right)$ but no effect of Repetition and no interaction between Prime Type and Repetition (both $F$ close to 1$)$. 


\subsection{Discussion}

Consistent with results in the literature, facilitation was found for both semantic and rime priming. The size of the semantic priming effect was very large, even on first presentation $(171 \mathrm{~ms})$. Using spoken words, primary associates as related items and lexical decision, Radeau (1983) also found a large facilitatory effect of semantic priming of $123 \mathrm{~ms}$. For rime priming, a $95 \mathrm{~ms}$ facilitatory effect was obtained on first presentation which is close to the $89 \mathrm{~ms}$ effect obtained by Radeau et al. (1995) (Experiment 1) with the same ISI $(20 \mathrm{~ms})$, the same task, and a proportion of rime trials slightly lower $(17 \%)$ in the present experiment than in the previous one $(25 \%)$.

Error rate was relatively high, both for first and for second presentation. As already suggested by Radeau et al. (1995), who found the same pattern of errors, this may be due to the use of short monosyllabic items which are more difficult to recognize than longer words (Grosjean, 1985; Bard et al., 1988).

The finding of an interaction between repetition and type of prime (semantic vs rime) imply that repetition effects depend upon the specific computations performed on the words. This result will be discussed further in light of the ERPs data.

\section{Experiment 2}

The aim of Experiment 2 was 2-fold. First, we wanted to study the electrophysiological correlates of the semantic and phonological priming effects reported in Experiment 1. We used a lexical decision task with response to pseudowords only, so that ERPs to words were not contaminated by motor-related processes. Of most interest was to determine whether both semantic and phonological priming would exert their influence on same or different ERP components. Second, it was important to determine whether repetition would influence the electrophysiological marker(s) of semantic and phonological priming similarly.

\section{1. Method}

\subsubsection{Participants}

Twentyone native French speakers, students at the Aix Marseille University, were paid for their participation in the experiment that lasted for about $1 \mathrm{~h}$. The data from three participants were discarded due to technical problems. All 18 participants (age range 19-27, mean $=22.5$ years; 7 women) but two were righthanded according to selfreport; two of the right handed participants had a left-handed relative in his or her immediate family. All participants had normal or corrected-tonormal vision and reported no hearing defect.

\subsubsection{Materials}

The very same stimuli were used as in the RT experiment. 
2.1.3. Design and procedure

As for the RT experiment, the prime and target stimuli were played through a D/A converter. The experiment was controlled by a Compaq 486 personal computer. At the beginning of the experiment, participants were given the same instructions as in the RT experiment but their task was to respond to the second item only when it was a pseudoword. This change was introduced in order to study priming effects for words uncontaminated by motor related potentials. Participants were also asked to avoid blinking from the onset of the prime word until an auditory click was presented, $2000 \mathrm{~ms}$ after target word onset; they were trained to blink between trials. Following the instructions, the participants listened to a practice set of 12 trials. The first block of trials was then presented.

\subsubsection{Recordings}

EEG was recorded via $\mathrm{Ag}-\mathrm{AgCl}$ electrodes from seven scalp sites: three along the midline at $F_{\mathrm{z}}, C_{\mathrm{z}}$ and $P_{\mathrm{z}}$ and two lateral pairs over anterior-temporal regions $\left(F_{7}\right.$ and $\left.F_{8}\right)$ and over posterior-temporal regions $\left(T_{5}\right.$ and $\left.T_{6}\right)$, each referred to the left mastoid. Eye movements and blinks were monitored via an electrode on the lower orbital ridge referred to the left mastoid.

The EEG was amplified by Grass P5 RPS107 amplifiers with a 0.01-30 Hz (half-amplitude cutoff) bandpass. The sampling rate was $250 \mathrm{~Hz}$. Approximately $10 \%$ of the trials were contaminated with eye movements or muscle artefacts; these were rejected off-line. Electrode impedances never exceeded $3 \mathrm{kOhms.}$

\subsubsection{Data analysis}

ERPs were averaged off-line for a $2200 \mathrm{~ms}$ epoch, within each condition for each subject and time-locked to the onset of target stimulus. The ERP data were analyzed by computing the mean amplitude in selected latency windows relative to a $200 \mathrm{~ms}$ pre-target baseline. Repeated measures analyses of variance (ANOVAs) were carried out with the Greenhouse-Geisser correction for inhomogeneity of variance applied where appropriate; reported are the uncorrected degrees of freedom, the epsilon value, and probability level following correction. Unless specified, Tukey (HSD) tests were used to test the significance of post-hoc comparisons.

\subsection{Results}

\subsubsection{First presentation}

As can be seen in Fig. 1 (left column), an $N_{1}-P_{2}$ complex was elicited by the presentation of the target word. Following the $N_{1}-P_{2}$ a large negative component, peaking around $450 \mathrm{~ms}$, that we refer to as $\mathrm{N} 400$, was elicited by the three types of stimuli. The N400 component was smallest to target words semantically related to the prime, intermediate to phonologically related target words and largest to control words. These priming effects were mainly localized between 300 and $800 \mathrm{~ms}$ post-target onset, but from $800 \mathrm{~ms}$ to the end of the recording period, the ERP traces were still most positive to semantically related targets, intermediate to phonologically related targets and less positive to control targets. 


\section{First presentation}
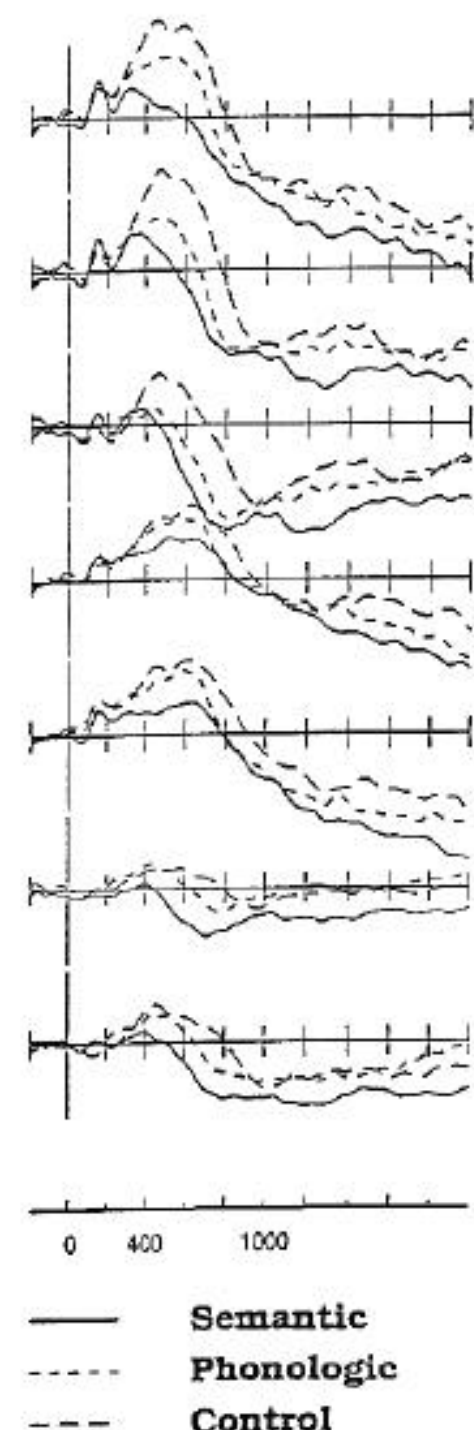

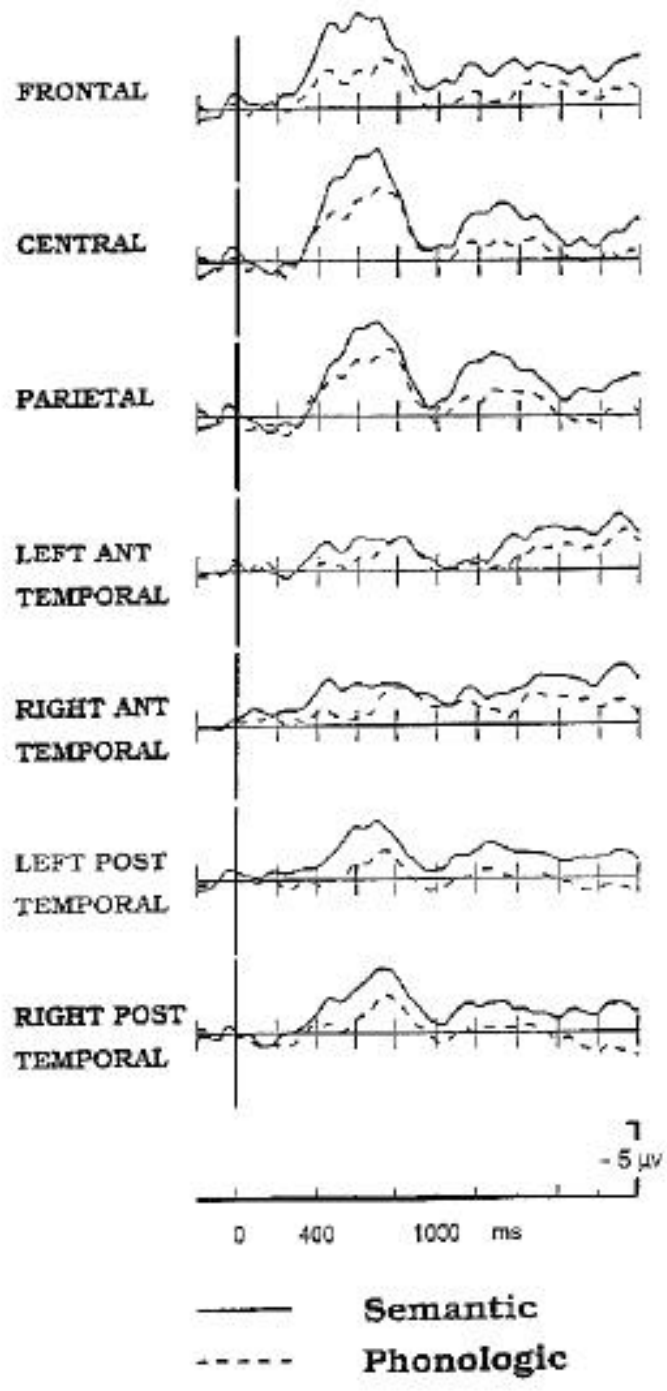
presentation. (Right) Difference waves calculated for the semantic priming effect (control minus semantic) and the phonological priming effect (control minus phonologic). On this figure, as on the following ones, the amplitude of the effect is represented in ordinate and time in abcissa. Time 0 represents target onset. Negative is up. 
Two-way repeated measures ANOVAs, including Prime Type (semantic, phonologic and control) and Electrode (7 levels) as factors, were performed in successive latency bands post-target presentation. Based on previous results (Besson et al., 1992; Holcomb and Neville, 1990) and on visual inspection, the mean amplitude of the $N_{1}-P_{2}$ was measured in the $0-300 \mathrm{~ms}$ latency band; the N400 component and the late positivity were measured in the $300-800$ and $800-2000 \mathrm{~ms}$ latency ranges, respectively.

Analysis of the mean amplitude of the $N_{1}-P_{2}$, in the 0-300 ms latency and, did not reveal any significant differences as a function of Prime Type $(F<1)$ nor any Prime Type $\mathrm{x}$ Electrodes interaction $(F<1)$.

Analysis in the $300-800 \mathrm{~ms}$ latency band showed a main effect of Prime Type ( $F$ $(2,34)=10.09, \mathrm{MSe}=36.47, \epsilon=0.96, p<0.001$ ). Post-hoc comparisons (Tukey HSD) revealed that the $\mathrm{N} 400$ was significantly smaller for targets that were semantically $(0.30 \mu \mathrm{V})$ than phonologically $(-1.40 \mu \mathrm{V})$ related to the prime words, that were in turn smaller than control targets $(-3.11 \mu \mathrm{V})$. The interaction between the effects of Prime Type and Electrode was significant $(F(6,102) 11.95$, MSe $=$ $11.25, \epsilon=0.61, p<0.001$ and $F(12,204)=2.76, \mathrm{MSe}=3.79, \epsilon=0.35, p<0.03$, respectively). Results of ANOVAs including lateral electrodes only showed that the mean amplitude in this latency band was more negative over anterior $(-3.05 \mu \mathrm{V})$ than posterior lateral locations $(-0.15 \mu \mathrm{V} ; F(1,17)=22.75, \mathrm{MSe}=19.97, p<$ 0.001). No difference was found in N400 amplitude between the left and right hemispheres $(F<1)$.

Finally, analysis in the 800-2000 ms latency band showed that the main effect of Prime type almost reached significance $(F(2,34)=3.17, \mathrm{MSe}=47.310, \epsilon=0.98$, $p<0.05)$ but the Prime type by Electrodes interaction was not significant $(\mathrm{F}<1)$.

To directly compare semantic and phonological priming effects and their scalp distribution, analyses were also performed on the difference waves (control minus semantic and control minus phonologic; see Fig. 1, right column). Results showed that semantic priming $(-3.41 \mu \mathrm{V})$ was significantly larger than phonological priming $(-1.71 \mu \mathrm{V} ; F(1,17)=4.29, \mathrm{MSe}=42.8, p<0.05)$. Although semantic priming seemed larger than phonological priming at frontal than parietal electrodes, the Priming by Electrodes interaction was not significant $(F<1)$.

Fine-grained $50 \mathrm{~ms}$ epoch analyses were also performed on the difference waves to determine when the ERP effects start to diverge. Across electrode locations, semantic priming was significantly larger than phonological priming from 450 to $700 \mathrm{~ms}$ (the $F$ values were comprised between 2.4 and 10.84, all $p<0.03$ ). From 1000 to $1600 \mathrm{~ms}$ post-target onset, semantic priming also seemed larger than phonological priming but this difference did not reach significance $(F(1,17)=2.58$, $\mathrm{MSe}=52.21, p=0.12$ )

\subsubsection{Second presentation}

As can be seen in Fig. 2 (left column), effects similar to those found for first presentation were found when the prime-target pairs were repeated: the N400 was smallest to semantically related words, intermediate to phonologically related words and largest to control words. However, as can clearly be seen from the difference 


\section{Second presentation}
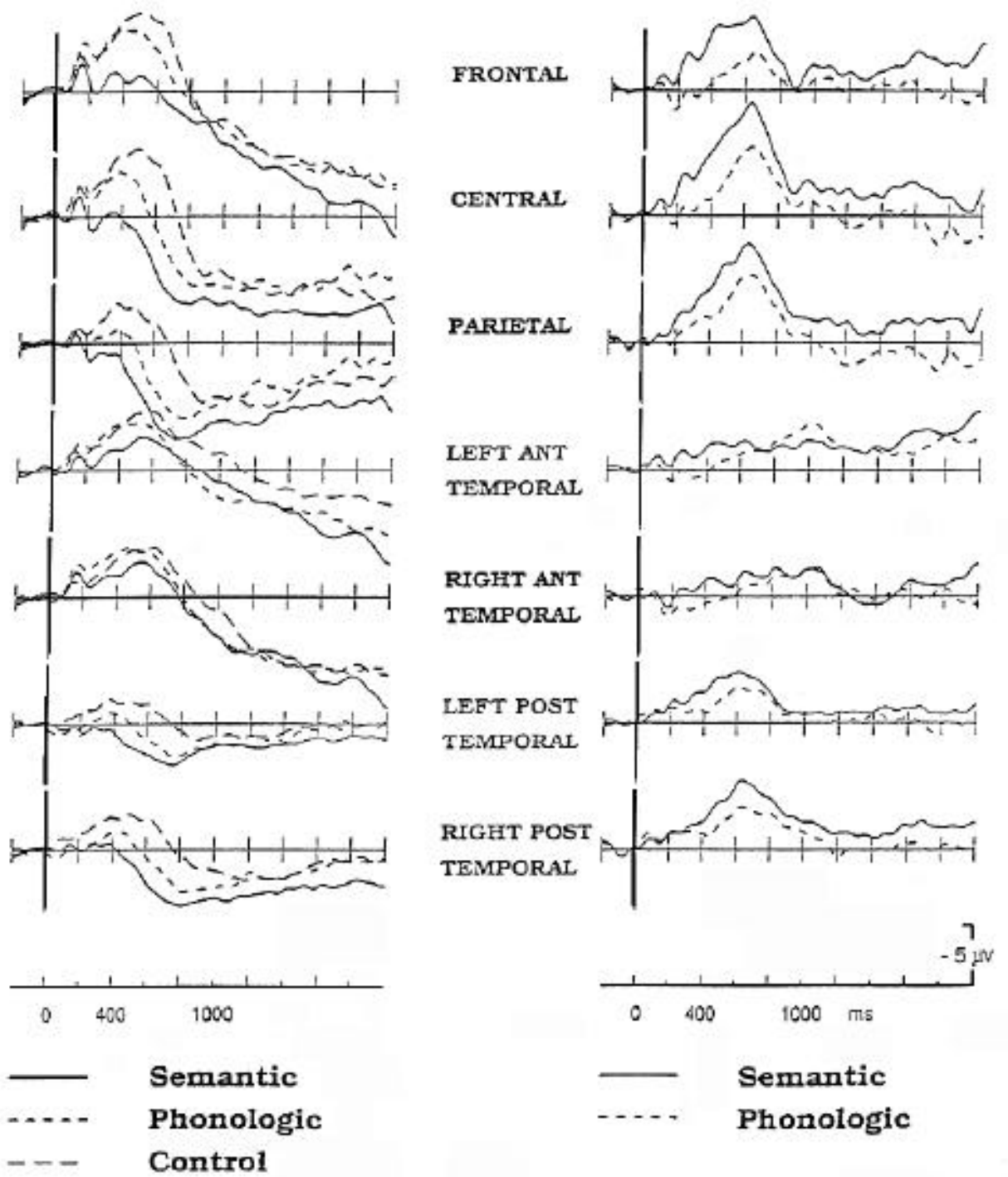

Fig. 2. (Left) Grand average ERPs for semantic, phonologic and control trials on second presentation (Right) Difference waves calculated for the semantic priming effect (control minus semantic) and the phonological priming effect (control minus phonologic). 
waves (right columns of Figs. I and 2), the phonological and semantic priming effects have a shorter onset latency on repetition than on first presentation. The same ANOVAs as for first presentation were conducted on the ERPs elicited on repetition.

Analysis of the mean amplitude of the $N_{1}-P_{2}$, in the 0-300 ms latency band, did not show any main effects of Prime Type $(F(2,34)=2.20$, MSe $=14.42, \epsilon=0.80$, $p=0$. 12) nor any interaction with the effects of Electrodes $(F(12,204)=1.92$, MSe $=1.79, \in=0.39, p=0.11)$. Note, however, that the $N_{1}$ component to phonologically related target words seemed larger than the $N_{1}$ to semantically related targets at some scalp sites (see Fig. 2, left column). Indeed, results in the 150-200 ms latency band revealed a significant Prime Type by Electrodes interaction (F $(12,204)=2.73, \mathrm{MSe}=3.15, \in=0.34, p<0.03)$. Post-hoc Tukey tests showed that $N_{1}$ was significantly larger to phonological than semantic targets at midline locations (frontal, central and parietal). No differences were found between phonologically related and control target words.

Analysis in the 300-800 ms latency band showed a main effect of Prime Type ( $F$ $(2,34)=28.18, \mathrm{MSe}=17.71, \epsilon=0.92, p<0.001)$. N400 was significantly smaller to targets that were semantically $(1.13 \mu \mathrm{V})$ than phonologically $(-0.85 \mu \mathrm{V})$ related to the prime words, that were, in turn, smaller than control targets $(-2.84 \mu \mathrm{V})$. The interaction between the effects of Prime Type and Electrode was significant ( $F$ $(12,204)=6.01, \mathrm{MSe}=3.27, \epsilon=0.32, p<0.001$, respectively). Results of lateral analyses showed that, as found for first presentation, the mean amplitude was more negative over anterior $(-2.79 \mu \mathrm{V})$ than posterior lateral locations $(-0.31 \mu \mathrm{V} ; F$ $(1,17)=31-3.03, \mathrm{MSe}=15.77, p<0.001)$. No differences were found between the left and right hemispheres.

Finally, analyses in the 800-2000 ms latency band revealed a main effect of Prime Type $(F(2,34)=3.42$, M.Se $=129.83, \in=0.95, p<0.04)$. The late positivity was larger for semantically $(4.89 \mu \mathrm{V})$ and phonologically $(3.58 \mu \mathrm{V})$ related targets than for control targets $(3.17 \mu \mathrm{V}$; see Fig. 2, left column). The Prime $\mathrm{x}$ Electrodes interaction was not significant $(F(12,204)=1.11, \mathrm{MSe}=5.359, \in=0.31, p=0.35)$.

Analyses of the difference waves (see Fig. 2, right column) showed that semantic priming $(-3.98 \mu \mathrm{V})$ was larger than phonological priming $(-1.99 \mu \mathrm{V} ; F(1,17)=$ 17.44, $\mathrm{MSe}=14.23, p<0.001)$. The Priming by Electrodes interaction was also significant which reflected the fact that the difference between both types of priming was largest frontally $(F(6,102)=2.92, \mathrm{MSe}=2.79, \in=0.53, p<0.04)$.

Fine-grained $50 \mathrm{~ms}$ epoch analyses were also performed on the difference waves to determine when semantic and phonological priming started to diverge (see Fig. 2, right column). Across electrode locations, semantic priming was significantly larger than phonological priming from 250 to $800 \mathrm{~ms}$ (the $F$ values were comprised between 4.4 and 14.8, all $p<0.02$ ). While this difference seems to last until the end of the recording period at midline sites, results show that neither the main effect of Prime Type, nor the Prime Type by Electrodes interaction were significant in the $1000-1600 \mathrm{~ms}$ latency band $(F(1,17)=2.56, \mathrm{MSe}=26.08, p=0.12$ and $F$ $(6,102)=1.54, \mathrm{MSe}=5.20, \epsilon=0.48, p=0.21)$. 


\section{SEMANTIC PHONOLOGIC CONTROL}
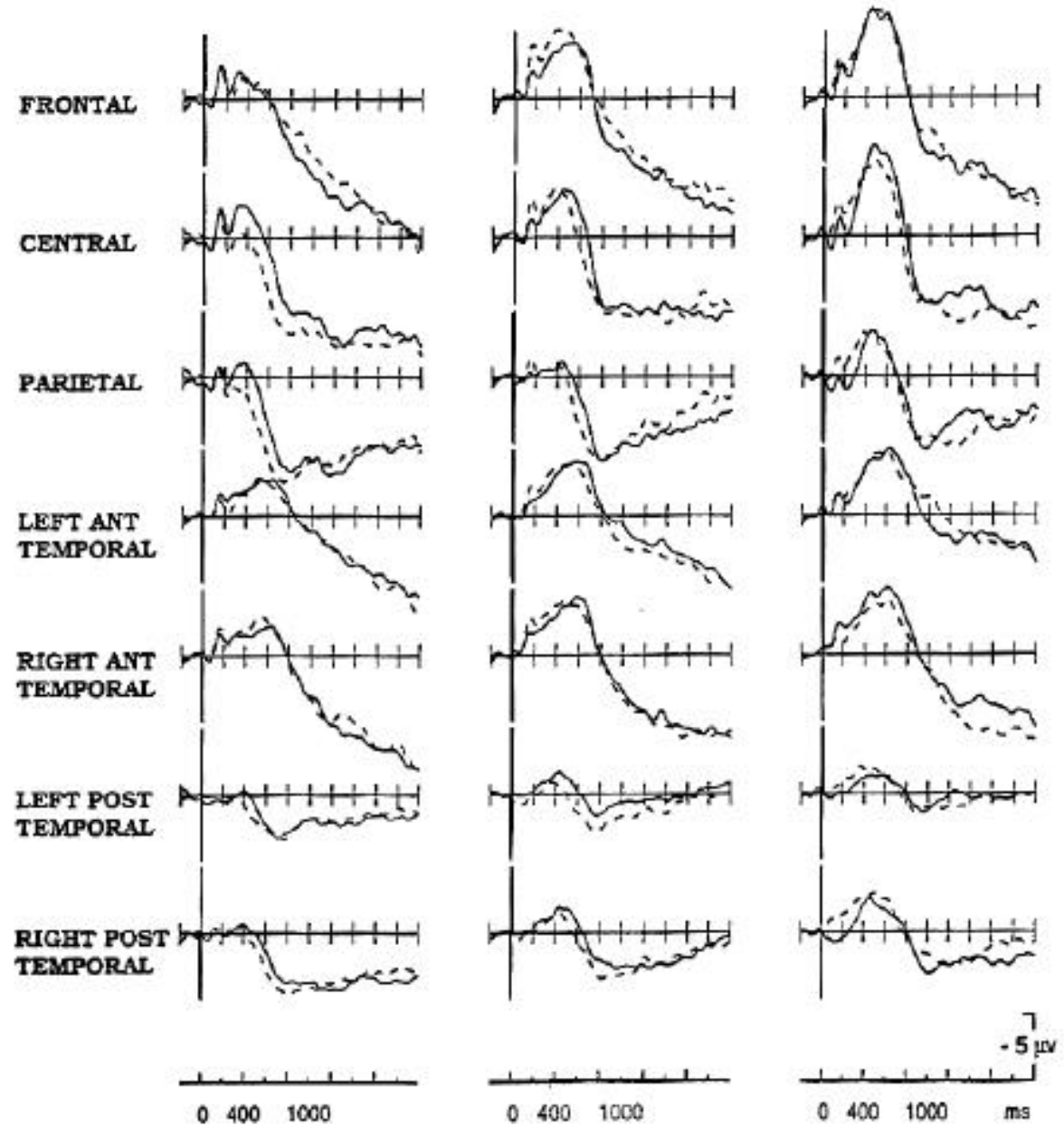

- First presentation

..... Second presentation

Fig. 3. Comparison of ERPs recorded on first and second presentations for semantically and phonologically related targets and for unrelated (control) targets.

Finally, a direct comparison of first and second presentation (see Fig. 3) revealed that the repetition effect was only significant for semantically related pairs in the 300-600 ms range (repetition by electrodes interaction, $F(6,102)=8.96$, $\mathrm{MSe}=$ $2.72, p<0.04)$. 


\subsection{Discussion}

\subsubsection{Summary of results}

Results on first presentation showed clear evidence of both semantic and phonological priming: semantically and phonologically related words were associated with smaller N400s than control targets. In line with results of previous experiments (McCallum et al., 1984; Holcomb and Neville, 1990; Connolly and Philips, 1994; Praamstra et al., 1994), these priming effects started around 300 $\mathrm{ms}$ post-target onset. Furthermore, analyses of the difference waves demonstrated that, from 450 to $700 \mathrm{~ms}$, semantic priming was of larger magnitude than phonological priming and that their scalp distribution was not significantly different. Similar results were found on repetition with two exceptions. First, whereas on first presentation, semantic priming was larger than phonological priming for $250 \mathrm{~ms}$, from 450 to $700 \mathrm{~ms}$, on repetition the difference between semantic and phonological priming started earlier and lasted longer $(550 \mathrm{~ms}$, from 250 to $800 \mathrm{~ms}$ ). Second, the scalp distribution of the two priming effects was shown to be somewhat different with the largest difference between the two at frontal site $^{1}$. However, the small number of electrodes used in the present experiment, while allowing to address questions such as the similarity or difference of semantic and phonological priming and their time-course, does not allow to draw strong, conclusions on their scalp distribution (or the underlying generators). In addition, as the PET studies summarized in the Introduction suggest, the overlap or at least the spatial proximity between the cerebral regions activated by phonological and semantic processing does not easily allow to distinguish the activated areas. Thus, the difference reported here, while potentially interesting, will need to be addressed in further experiments using a larger number of electrodes.

\subsubsection{Phonological priming}

Regarding the ERP correlates of rime priming between spoken words, our results are consistent with those obtained by Praamstra et al. (1994) in a study already mentioned in the introduction. As in the present experiment, the effect of final phonological overlap was significant between 450 and $700 \mathrm{~ms}$ post target onset.

There are cases, however, in which no evidence for rime priming was reported. Recently, Van Petten et al. (1996) used sentences in which the final word was the expected completion or was incongruous but alliterated or rimed with the

\footnotetext{
1 The N400 component is typically slightly larger over the right than left posterior sites. The fact that we did not find any $\mathrm{N} 400$ lateralization effects in the present data may result from the inclusion in the averages of two left-handed participants and of two right-handed participants with left-handed relatives. Indeed, Kutas et al. (1988) have shown that the N400 asymmetry is larger in the absence of familial left-handedness. It may also result from the use of a left-mastoid reference, a choice determined by the small number of amplifiers available.
} 
expected completion (for example, 'The main highway was flooded so they had to take a long detour-detail-contour'). They showed that while a decrease in the amplitude of the $\mathrm{N} 400$ was found for final incongruous words that alliterated with the expected sentence completion, no effect was found for words that rimed. Thus, ERP evidence for rime priming seems to depend upon the stimuli used in the experiment and the task at hand, as has been demonstrated for semantic priming (Bentin et al., 1993).

2.3.3. Semantic and phonological priming influence the same ERP component?

Most importantly, the results reported in the present experiment clearly indicate that both phonological and semantic priming seem to exert their influence on the same ERP component, namely the N400. This interpretation is in line with results of Praamstra et al. (1994), O'Rourke and Holcomb (1992), but stands in marked contrast with the two-components interpretation proposed by Connolly and Philips (1994). Since this is an important point, their experiment is described in details. These authors used an elegant design in which sentences were presented auditorilly as connected speech. Sentence terminal words did or did not alliterate with the best sentence completion, and were semantically congruous or incongruous relative to the sentence context, thus, resulting in four independent conditions. The four examples provided in the article are the following: 'At night the old woman locked the door' (phonologically and semantically congruous); 'Phil put some drops in his icicles' (phonologically congruous and semantically incongruous with the expected completion eyes); 'They left the dirty dishes in the kitchen' (phonologically incongruous and semantically congruous with sink); 'Joan fed her baby some warm nose' (phonologically and semantically incongruous with milk) An early negative component, the phonological mismatch negativity (PMN), was shown to develop when words did not alliterate but were congruous relative to the sentence context. In contrast, a delayed $\mathrm{N} 400$ was observed when words alliterated but were semantically incongruous. Furthermore, both a PMN and an N400 were generated when words did not alliterate and were semantically incongruous. While they consider the PMN and the N400 as two independent components, this interpretation does not necessarily follow from their results. It may well be that the same ERP component (N400) was present in all conditions but that its latency was modulated by the different types of priming. In other words, compared to plain incongruous words, $\mathrm{N} 400$ is delayed for incongruous words that alliterate because, based on phonological analysis of the first phonemes, the incoming information is compatible with the best completion. Furthermore, N400s, rather than PMN, are elicited by congruous words that did not alliterate because terminal words were not the sentence best completion. Results of several experiments (see Kutas and Van Petten (1988), for review) have demonstrated that sentence terminal words do not need to be incongruous for an N400 to be generated; rather the amplitude of the N400 is inversely correlated with terminal word's cloze probability (Kutas et al., 1984). Thus, what Connolly and Philips 
(1994) describe as a PMN may very well be an N400 to low cloze probability endings. While we don't think that the N400 is necessarily a unitary phenomenon, Connolly and Phillips's data do not unambiguously demonstrate that there are two distinct ERP components, one sensitive to phonological priming, the PMN, and the other sensitive to semantic priming, the N400.

An interpretation in terms of phonological modulation of N400 latency is also supported by the results of Van Petten et al. (1996), mentioned above. In their experiment, they first determined each word isolation point using a gating procedure and then averaged ERPs time-locked to the isolation point. For words that alliterate, N400 was time-locked to the isolation point. For words that did not alliterate, the N400 started before the isolation point. Furthermore, when the words alliterate, the latency of the N400 to incongruous words was shorter when the isolation point was early than when it was late. Therefore, these results show strong evidence that the position of phonological overlap does modulate the latency of the N400 component.

2.3.4. Repetition effects

On repetition, results again showed clear evidence of both semantic and phonological priming: target words that were semantically or phonologically related to the prime words were associated with smaller N400 components than control targets. As found for first presentation, semantic priming was larger than phonological priming, but the difference started earlier and lasted longer. Furthermore, direct comparison between first and second presentations revealed that this was mainly due to larger and earlier effects of semantic priming on repetition than on first presentation. Indeed, while the $\mathrm{N} 400$ to semantically related targets was significantly smaller with repetition, no such repetition effects were found for phonologically related and control targets.

The finding that auditory semantic and phonological priming are differentially modulated by repetition provide interesting highlights to the debate between the abstractionist and episodic accounts of the repetition effect. Abstractionist views hold that facilitation in word processing on repetition reflects a higher level of activation in the corresponding lexical unit viewed as an abstract representation (Morton, 1979). In contrast, episodic accounts hold that repetition effects rely on memory for particular prior episodes. It is important to note that abstractionist views may be most appropriate to account for short-term repetition effects that have been shown, to dissipate rapidly, as was found in ERPs and repetition experiments using word lists (e.g. Rugg, 1984; Rugg et al., 1995). Episodic views, however, may be more appropriate to account for long-lasting repetition effects that can last for days (Monsell, 1985; Ratcliff et al., 1985), as was found in ERPs and repetition experiments using sentences (e.g. Besson et al., 1992). The shortlived effect would reflect facilitation of perceptual encoding processes while the long-term effect would be mediated by episodic memory traces and would be strategy-dependent (Oliphant, 1983; Forster and Davis, 1984). A relatively long 
lag $(20 \mathrm{mn})$ was used between first and second word's presentation in the present experiment. Thus, the finding of significant ERPs repetition effects for semantically related but not for phonologically related pairs indicates that while semantic information seems to be coded in the episodic memory traces left by the word pair's first presentation, phonological information was not. That repetition involved explicit episodic memory effects is likely since word pairs were repeated using the same pairing as on first presentation, so that the first word could be used as a cue to predict the second word of the pair. Furthermore, these results are in-line with those from previous behavioral experiments, conducted using the level-of-processing approach, showing that semantic processing yields better memory than phonological processing (e.g. Craik and Tulving, 1975).

Finally, on repetition, results showed that the amplitude of the $N_{1}$ component was larger for phonologically than semantically related pairs. This early priming effect may reflect facilitation of perceptual encoding processes. Such short-lived perceptual priming that arise while participants are listening to phonologically related items would have vanished by the time the phonological pair was repeated which would explain the lack of repetition effect in this case. Another interpretation needs to be considered, however. This early difference between semantically and phonologically related words may be linked with the fact that, on repetition, semantic priming onsets earlier than phonological priming. Thus, this early priming effect would reflect modulations of the $\mathrm{N} 400$ component rather than modulations of the $N_{1}$ component. Evidence favoring this latter interpretation comes from the observation that the difference between semantically and phonologically related words was as large over posterior-temporal regions, where the $N_{1}$ component was essentially absent, as over fronto-central regions, where the $N_{1}$ component was clearly identifiable. These two interpretations can be desentangled in further experiments, in which both semantically and phonologically related pairs will be repeated within the same blocks of trials so that the repetition lag will be shorter than in the present experiment. If the first interpretation is correct, we should find repetition effects for phonologically related pairs, as well as for semantically related pairs. In contrast, if the second interpretation is valid, we should again only find an early priming effect for semantically related pairs. Taken together, our results suggest that while perceptual priming may account for both phonological and semantic priming, only semantic information is encoded in the episodic memory trace and account for the facilitation in word's processing found on repetition.

\section{Acknowledgements}

The work reported herein was supported by grants ARC (96/01-203) and FRFC (2.4526.94) to M. Radeau, GIS 'Science de la Cognition' (1995-1997) to M. Besson, E. Bigand and M. Habib and JNICT (Grant BLS3/96) to S.L. Castro. We want to thank two anonymous referees for their useful comments. 
Appendix A. Words used as critical items

\begin{tabular}{|c|c|c|c|c|c|c|c|}
\hline Semantic & \multicolumn{2}{|c|}{ Prime rime Control } & Target & Semantic & \multicolumn{2}{|c|}{ Prime rime Control } & Target \\
\hline BEAU & QUAI & BAS & LAID & PLEUR & CHARME & FRONCE & LARME \\
\hline FAON & MICHE & CAVE & BICHE & LION & MIGRE & LOURDE & TIGRE \\
\hline NOIR & CRAN & CHâLE & BLANC & PAGE & GIVRE & BèCHE & LIVRE \\
\hline SCIE & POIDS & RAIE & BOIS & JAUNE & TERRE & TENTE & VERT \\
\hline NEZ & DOUCHE & CAS & BOUCHE & DOIGT & NAIN & SOU & MAIN \\
\hline SPHèRE & COULE & ZONE & BOULE & BIèRE & POUSSE & TAUPE & MOUSSE \\
\hline TABLE & THèSE & CORDE & CHAISE & VERTE & CURE & CALQUE & MURE \\
\hline CHIEN & TAS & DON & CHAT & SKI & BEIGE & TASSE & NEIGE \\
\hline FROID & MAUX & TRONC & CHAUD & JOUR & PUIT & TACHE & NUIT \\
\hline BLEU & MIEL & TOGE & CIEL & OEUF & SOUL & SUR & POULE \\
\hline QUATRE & ZINC & TERNE & CINQ & GUERRE & MAI & TORT & PAIX \\
\hline SOMBRE & TRAIRE & BROSSE & CLAIR & SABLE & RAGE & SONDE & PLAGE \\
\hline LONG & TOUR & PONT & COURT & POIVRE & BELLE & CARTE & SEL \\
\hline AIGRE & ROUX & PIE & DOUX & FRUIT & GOMME & SINGE & POMME \\
\hline ONZE & BOUSE & RHUM & DOUZE & LAINE & BULLE & SOMME & PULL \\
\hline DRAP & RIZ & TROP & LIT & ROI & SCèNE & SOLE & REINE \\
\hline GAUCHE & MOITE & VISSE & DROITE & TOUT & TIEN & BANC & REN \\
\hline MOU & PUR & VIF & DUR & CLOWN & SIRE & $\mathrm{BAC}$ & RIRE \\
\hline PILE & MASSE & TUBE & FACE & CERCLE & THON & GERME & ROND \\
\hline TIGE & COEUR & VACHE & FLEUR & ROUGE & LENT & POT & SANG \\
\hline PRêTRE & LOI & BRUSQUE & EFOI & FRèRE & BEURRE & TRANCHE & SOEUR \\
\hline CUBE & NORME & MARCHE & FORME & SOIF & TEINT & RANG & FAIM \\
\hline FAIBLE & SORT & GOURDE & FORT & LOUCHE & COUPE & BAL & SOUPE \\
\hline TRISTE & TAIE & CHOU & GAIE & FRAISE & LUCRE & COURSE & SUCRE \\
\hline MAIGRE & CLOS & SOURDE & GROS & NORD & RUDE & BANQUE & SUD \\
\hline HOMME & RAME & BISE & FEMME & RAIL & CRIN & PLAT & TRAIN \\
\hline JAMBE & GRAS & VOTE & BRAS & PLEIN & RIDE & FREIN & VIDE \\
\hline Dé & PEU & NID & JEU & RUE & CIL & BASE & VILLE \\
\hline ROBE & DUPE & VEINE & JUPE & PAIN & REIN & GANT & VIN \\
\hline POIRE & PUS & NOEUD & JUS & BAIN & SERRE & GENS & MER \\
\hline
\end{tabular}

\section{References}

Bard, E.G., Shillcock, R.C., Altmann, G.T.M., 1988. The recognition of words after their acoustic offsets in spontaneous speech: effects of subsequent context. Percept. Psychophys. 44, 395-408.

Bentin, S., McCarthy, G., Wood, C., 1985. Event-related potentials, lexical decision and semantic priming. Electroencephalography Clin. Neurophysiol. 60, 343-355. 
Bentin, S., Kutas, M., Hillyard, S., 1993. Electrophysiological evidence for task effects on semantic priming in auditory word processing. Electrophysiology 30, 161-169.

Besson, M., Kutas, M., Van Petten, C., 1992. An event-releted potential (ERP) analysis of semantic congruity and repetition effects in sentences. J. Cogn. Neurosci. 4, 132-149.

Besson, M., Faita, F., Czternasty, C., Kutas, M., 1997. What's in a pause: event-related potential analysis of temporal disruptions in written and spoken sentences. Biol. Psych. 46, 3-23.

Connolly, J.F., Philips, N.A., 1994. Event-related potential components reflect phonological and semantic processing of the terminal word of spoken sentences. J. Cogn. Neurosci. 6, 256-266.

Content, A., Mousty, P., Radeau, M., 1990. BRULEX. Une base de données lexicales informatisée pour le français écrit et parlé. L'Année Psychologique 90, 551-566.

Craik, F.I.M., Tulving, E., 1975. Depth of processing and the retention of words in episodic memory. J. Exp. Psych. Gen. 104, 268-294.

Démonet, J.-F., Chollet, F., Ramsay, S., Cardebat, D., Nespoulous, J.-L., Wise, R., Rascol, A., Frackowiak, R., 1992. The anatomy of phonological and semantic processing in normal subjects. Brain 115, 1753-1768.

Ellis, A.W., Young A.W., 1988. Human Cognitive Neuropsychology. Lawrence Erlbaurn Ass, Hillsdale, NJ.

Ellis, A.W., 1982. Modality-specific repetition priming of auditory word recognition. Curr. Psych. Res. 2, 123-128.

Emrnorey, K.D., 1989. Auditory morphological priming in the lexicon. Lang. Cogn. Proc. 4, 73-92.

Fiez, J., Raichle, M., Balota, D., Tallal, P., Petersen, S., 1996. PET activation of posterior temporal regions during auditory word presentation and verb generation. Cereb. Cortex 6, 1-10.

Forster, K., Davis, C., 1984. Repetition priming and frequency attenuation in lexical access. J. Exp. Psych. Learn. Mem. Cogn. 110, 680-698.

Goldinger, S.D., Luce, P.A., Pisoni, D.B., Marcario, J.K., 1992. Form-based priming in spoken wor recognition: the roles of competition and bias. J. Exp. Psych. Learn. Mem. Cogn. 18, 1211-1238.

Grosjean, F., 1985. The recognition of words after their acoustic offset: evidence and implications. Percept. Psychophys. 38, 299-310.

Holcomb, P.J., Neville, H.J., 1990. Auditory and visual semantic priming in lexical decision: A comparison using event-related brain potentials. Lang. Cogn. Proc. 5, 281-312.

Howard, D., Patterson, K., Wise, R., Brown, D., Friston, K., Weiller, C., Frackowiak, R., 1992. The cortical localizations of the lexicons. Positron emission tomography evidence. Brain 115, 1769-1782.

Kutas, M., Hillyard, S.A., 1980. Reading senseless sentences: Brain potentials reflect semantic incongruity. Science $207,203-205$

Kutas, M., Van Petten, C., 1988. Event-related potential studies of language. In: Ackles, P.K., Jennings, J.R., Coles, M.G.H. (Eds.), Advances in Psychophysiology. JAI Press, Greenwich, Connecticut, Vol. 3, pp. 139-187.

Kutas, M., Lindamood, T., Hillyard, S.A., 1984. Word expectancy and event-related brain potentials during sentence processing. In: Kornblum, S., Requin, J. (Eds.), Preparatory States and Processes. Lawrence Erlbaum, Hillsdale, pp. 217-237.

Kutas, M., Van Petten, C., Besson, M., 1988. Event-related potential asymetries during the reading of sentences. Electroencephalography Clin. Neurophys. 69, 218-233.

Lupker, S.J., 1984. Semantic priming without association: a second look. J. Verb. Learn. Verb. Behav. $23,709-733$.

Marslen-Wilson, W.D., Welsh, A., 1978. Processing interactions and lexical access during word recognition in continuous speech. Cogn. Psych. 10, 29-63.

Mazoyer, B.M., Tzourio, N., Frak, V., Syrota, A., Murayama, N., Levrier, 0., Salamon, G., Dehaene, S., Cohen, L., Mehler, J., 1993. The cortical representation of speech. J. Cogn. Neurosci. 5, 467-479.

McCallum, W.C., Farmer, S.F., Pocock, P.V., 1984. The effects of physical and semantic incongruities on auditory event-related potentials. Electroencephalography Clin. Neurophys. 59, 477-488.

Meyer, D.E., Schvaneveldt, R.W., 1971. Facilitation in recognizing pairs of words: Evidence of a dependence between retrieval operations. J. Exp. Psych. 90, 227-234.

Mitchell, P., Andrews, S., Ward, P., 1993. An event-related potential study of semantic congruity and repetition in a sentence reading task: effects of context change. Electrophysiology 30, 496-509. 
Monsell S., 1985. Repetition and the lexicon. In: Ellis, A.W. (Ed.), Progress in the Psychology of Language. Lawrence Erlbaurn, Hillsdale, NJ, Vol. 2, pp. 147-195.

Morton, J., 1979. Facilitation in word recognition experiments leading to changes in the logogen model. In: Kolers, P., Wrolstad, M., Bourna, H. (Eds.), Processing Of Visible Language, 1. Plenum Press, New-York

Neely, J.H., 1990. Semantic priming effects in visual word recognition: A selective review of curren findings and theories. In: Besner, D., Humphreys, G. (Eds.), Basic Processes in Reading: Visual Word Recognition, Erlbaum, Hillsdale, NJ.

Nobre, A.C., McCarthy, G., 1994. Language-related ERPs: scalp distributions and modulation by word type and semantic priming. J. Cogn. Neurosci. 6, 233-255.

O'Rourke, T., Holcomb, P.J., 1992. Electrophysiological evidence for the time course of spoken word recognition. Tenth International Conference on Even t-Related Potentials of the Brain, EPIC, 1992, p. 120.

Oliphant, G.W., 1993. Repetition and recency effects in word recognition. Aust. J. Psych. 35, 393403.

Petersen, S.E., Fox, P.T., Posner, M.I., Mintun, M., Raichle, M.E., 1988. Positron emission tomographic studies of the cortical anatomy of single-word processing. Nature 331, 585-589.

Petersen, S.E., Fox, P.T., Snyder, A.Z., Raichle, M.E., 1990. Activation of extrastriate and fronta cortical areas by visual words and word-like stimuli. Science 249, 1041-1044.

Praamstra, P., Meyer, A.S., Levelt, W.J.M., 1994. Neurophysiological manifestations of phonological processing: latency variation of a negative ERP component timelocked to phonological mismatch. J. Cogn. Neurosci. 6, 204-219.

Radeau, M., Morais, J., Dewier, A., 1989. Phonological priming in spoken word recognition: task effects. Mem. Cogn. 17, 525-535

Radeau, M., Segui , J., Morais , J., 1994. The effect of overlap position in phonological priming between spoken words. Proceedings of the International Conference on Spoken Language Processing, Yokohama, pp. 119-1422.

Radeau, M., Morais, J., Segui, J., 1995. Phonological priming between monosyllabic spoken words. J. Exp. Psych. Hum. Percept. Perf. 21, 1297-1311

Radeau, M., 1983. Semantic priming between spoken words in adults and children. Can. J. Psych. 37 547-556.

Ratcliff, R., Hockley, W., McKoon, G., 1985. Components of activation: repetition and priming effects in lexical decision and recognition. J. Exp. Psych. Gen. 114, 435-450.

Rosenzweig, M., 1970. International Kent Rosanoff word association norms, emphasizing those of French male and female students and French workmen. In: Postman, L., Keppel, G. (Eds.), Norms of Word Association, Academic Press, New York.

Rugg, M., Doyle, M.C., Wells, T., 1995. Word and nonword repetition within- and across-modality: An event-related potential study. J. Cogn. Neurosci. 7, 209-227.

Rugg, M., 1984. Event-related potentials and the phonological processing of words and nonwords. Brain Lang. 23, 225-240

Rugg, M., 1987. Dissociation of semantic priming, word and nonword repetition by event-related potentials. Quart. J. Exp. Psych. 39A, 123-148.

Scarborough, D.L., Cortese, C., Scarborough, H., 1977. Frequency and repetition effects in lexica memory. J. Exp. Psych. Hum. Percept. Perf. 3, 1-17.

Slowiaczek, L.M., Hamburger, M.B., 1992. Prelexical facilitation and lexical interference in auditory word recognition. J. Exp. Psych. Learn. Mem. Cogn. 18, 1239-1250.

Slowiaczek, L.M., Pisoni, D.B., 1986. Effects of phonological similarity on priming in auditory lexical decision. Mem. Cogn. 14, 230-237.

Slowiaczek, L.M., 1994. Semantic priming in a single-word shadowing task. Am. J. Psych. 107, 245-260.

Swinney, D.A., Onifer, W., Prather, R., Hirshkowitz, M., 1979. Semantic facilitation across sensory modalities in the processing of individual words and sentences. Mem. Cogn. 7, 159-165. 
Van Petten, C., Rubin, S., Plante, E., Parks, M., 1996. When does phonology meet semantics? ERP evidence of early semantic processing. Paper presented at the Sixth International Conference on Cognitive Neurosciences, May, Asilomar, CA.

Wise, R., Chollet, F., Hadar, U., Friston, K., Hoffner, E., Frackowiak, R., 1991. Distribution of cortical neural networks involved in word comprehension and word retrieval. Brain 114, 1803-1817.

Zatorre, R.J., Evans, A.C., Meyer, E., Gjedde, A., 1992. Lateralization of phonetic and pitch discrimination in speech processing. Science 256, 846-849. 